\title{
O big business bias e os desafios para a indústria brasileira
}

The big business bias and the challenges to the brazilian industry

\author{
Fernanda Cimini Salles \\ fcimini@cedeplar.ufmg.br \\ Universidade Federal de Minas Gerais (UFMG)
}

\begin{abstract}
Resumo: O artigo investiga a presença de mecanismos de favorecimento a grandes negócios (big business bias) e seu impacto no ambiente de negócios no Brasil. A partir da análise de instituições-chave na indústria brasileira, a saber, acesso à crédito, sistema de inovação e relações interfirmas, observa-se que a presença e forma de atuação de grupos econômicos não somente tornam a coordenação da atividade produtiva hierarquizada e assimétrica, como também ativam barreiras de entrada para criação de novas riquezas. $\mathrm{O}$ artigo conclui que os entraves para uma maior dinamização da indústria brasileira têm raízes em dinâmicas institucionais complexas, silenciadas no debate público.
\end{abstract}

Palavras-chave: Grupos Econômicos; Capitalismo Hierárquico; Indústria Brasileira

\begin{abstract}
The article investigates the presence of mechanisms favoring business groups (big business bias) and its impact on the business environment in Brazil. Looking at key institutions in the Brazilian productive regimes, namely, access to credit, innovation system and inter-firm relationship, the article argues that the way business groups organize themselves not only create hierarchical and asymmetrical relationships but also enable entry barriers to creating new wealth. The article concludes that the barriers to greater dynamism of the Brazilian industry are rooted in complex institutional dynamics, silenced in the public debate.
\end{abstract}

Key-words: Business Groups; Hierarchical Capitalism; Brazilian Industry 


\section{INTRODUÇÃO}

O Brasil convive há décadas com o desafio da transformação de sua base produtiva para a consolidação de um padrão industrial mais intensivo em conhecimento. Apesar do processo, de industrialização, brasileiro ter sido bem-sucedido na consolidação de setores altamente competitivos, tais como o setor aeronáutico, petroquímico, alimentício, farmacêutico e agronegócios, coexistem bolsões ainda muito distantes da fronteira tecnológica mundial - problema recorrentemente associado na literatura econômica à chamada "heterogeneidade estrutural". De acordo com a CEPAL, as brechas existentes entre setores, regiões e empresas com diferentes níveis de produtividade seriam um obstáculo para o crescimento inclusivo no país ${ }^{1}$.

Diante disso, a principal contribuição do artigo é oferecer uma perspectiva analítica ainda pouco explorada nas ciências econômicas para compreender esse desafio. Para tanto, recorre-se à literatura de Varieties of Capitalism ( $V o C$ ), abordagem teórica inicialmente proposta por Peter Hall e David Soskice (2001), e posteriormente desenvolvida por Ben Schneider (2013) para o capitalismo latino-americano. A contribuição central dessa abordagem, que tem sua origem na ciência política, é olhar para o processo de construção das instituições que orientam o comportamento dos atores econômicos, buscando identificar os arranjos institucionais e as relações de complementariedade que conformam diferentes tipos de capitalismo. Segundo essa literatura, o Brasil poderia ser classificado como "Capitalismo Hierárquico", modalidade em que as instituições seriam marcadas por relações hierárquicas excludentes, criando assimetrias e relações de desigualdade entre empresas, setores e regiões.

Nesse sentido, o problema de investigação que motiva o trabalho é saber por que o capitalismo brasileiro, em pleno século XXI, ainda não conseguiu desvencilhar-se de um legado conservador, aparentemente resistente a um padrão mais intensivo em conhecimento. A principal hipótese do trabalho diz respeito à existência de vícios institucionais (aqui denominados, big business bias) que favorecem grandes grupos econômicos no acesso a recursos essenciais para a atividade econômica: acesso a capital, inovação e relações interfirmas. Esses vícios criam entraves que dificultam a geração de novas riquezas e a diversificação da atividade econômica.

O maior desafio para avançar essa hipótese é a disponibilidade de dados específícos para os grupos econômicos brasileiros. Como inexiste uma base de dados que contemple a

\footnotetext{
${ }^{1}$ Ver documentos: A hora da igualdade: brechas por cerrar, caminhos por abrir (2010); Mudança estrutural para a igualdade: um enfoque integrado do desenvolvimento (2012) e Pactos para a igualdade: rumo a um futuro sustentável (2014), Por um desenvolvimento inclusivo: O Caso do Brasil (2015), da CEPAL.
} 
atuação desses grupos nos arranjos institucionais abordados nesse trabalho, faz-se necessário recorrer à categorização por porte da firma, adotando "grandes empresas" como proxy para grupos econômicos. ${ }^{2}$ Essa solução, embora não seja ideal, permite ao menos avançar na construção do argumento.

Assim, o artigo busca entender os dilemas de coordenação próprios do capitalismo brasileiro e em que medida os mecanismos hierárquicos de governança moldam as possibilidades de desenvolvimento da indústria brasileira. Especificamente, pretende-se examinar como a presença de grupos econômicos tem moldado o ambiente de negócios no Brasil, em especial, criando incentivos e constrangimentos para a atividade empreendedora. A fim de explorar o alcance da lógica de coordenação hierárquica sobre as atividades de empresários brasileiros membros e não membros da elite empresarial, o artigo se estrutura em três seções, além desta introdução e conclusão.

Na primeira delas, apresento a discussão da literatura e analiso porque a presença de grandes grupos econômicos importa na conformação de regimes produtivos em países de desenvolvimento tardio e, em especial, no Brasil. Na segunda seção, identifico as complexas relações entre pequenas, médias e grandes empresas que têm lugar na indústria brasileira, chamando atenção para a ocorrência do big business bias. Na terceira seção, exploro como as assimetrias existentes entre empresas pertencentes a grupos econômicos e empresas não pertencentes criam barreiras de entrada para a criação de novas riquezas. Por fim, o artigo conclui que os obstáculos observados no capitalismo brasileiro encontram raízes em dinâmicas econômicas e políticas silenciadas no debate público. Nesse sentido, o trabalho visa lançar luz a aspectos hierárquicos e assimétricos do nosso capitalismo, contribuindo para a inserção dessas questões na agenda política da indústria.

\section{ABORDAGEM TEÓRICA}

Com o fim da Guerra Fria e o triunfo do capitalismo democrático, esperava-se uma convergência em escala mundial dos modelos de organização da atividade produtiva.

\footnotetext{
${ }^{2}$ A definição de porte de empresas, adotada neste trabalho, seguiu a metodologia utilizada pelo IBGE e SEBRAE, baseada no número de pessoas ocupadas. Na indústria, considera-se microempresa a de 0 a 19 empregados, pequena empresa a de 20 a 99 empregados, média empresa a de 100 a 499 empregados e grande empresa a acima de 500 empregados. No comércio e serviços, considera-se microempresa a de 0 a 9 empregados, pequena empresa a de 10 a 49 , média empresa a de 50 a 99 e grande empresa a acima de 100 empregados. A categoria micro e pequena empresa (MPE) representa a soma das empresas de micro e pequeno porte, respeitando as diferenças entre os setores industrial e terciário.
} 
Contudo, as trajetórias históricas, institucionais e culturais de cada sociedade revelaram-se fundamentais para delinear a forma como capital, trabalho e governo atuam nos regimes industriais. O resultado é a emergência não apenas de um único capitalismo global, mas de uma variedade de capitalismos, que se diferenciam na dinâmica dos mercados de trabalho, dos mercados de capitais, dos regimes de qualificação da mão de obra, dos sistemas de inovação, das estruturas empresariais, das políticas de bem-estar social, dentre outros aspectos institucionais.

Em Varieties of Capitalism (doravante VoC), Peter Hall e David Soskice (2001) sistematizaram essas variedades observadas nas sociedades industriais segundo os seus mecanismos de coordenação e governança. A partir da premissa de que a natureza de coordenação entre as firmas é um fator central para determinar as características fundamentais de um regime produtivo, a abordagem $\mathrm{VoC}$ argumenta que as instituições mais importantes que conferem singularidade a uma sociedade industrial serão aquelas que condicionam a lógica da coordenação entre os agentes econômicos.

A abordagem VoC ganhou proeminência no debate acadêmico a partir da distinção entre dois tipos ideais de economia política, nos quais, hipoteticamente, instituições e estratégias produtivas se reforçam mutuamente e produzem resultados eficientes. Esses tipos ideias são: economias de mercado liberal, cujo modelo mais se aproximaria aos Estados Unidos; e economias de mercado coordenado, que se aproximaria ao caso alemão. O primeiro modelo caracteriza-se pela preponderância de relações de curto prazo, pautadas no preço (lei da oferta e demanda), na coordenação entre agentes econômicos. O segundo modelo caracteriza-se pela preponderância de relações de médio e longo-prazo no estabelecimento de compromissos formais e informais entre os agentes econômicos. ${ }^{3}$

No esforço de expandir as contribuições conceituais da abordagem VoC para além das economias avançadas, Ben Schneider (2004; 2009; 2013) propõe uma variedade de capitalismo adicional, típico das economias latino-americanas, denominada "economia de mercado hierárquico", que compreende um tipo de coordenação exercido unilateralmente, seja por um conjunto restrito de firmas, seja pelo próprio governo. Esse modelo é marcado por quatro importantes características: (i) concentração de empresas domésticas em um pequeno número de grupos econômicos diversificados; (ii) presença de multinacionais estrangeiras; (iii) baixa qualificação da força de trabalho e (iv) relações no mercado de

\footnotetext{
${ }^{3}$ Por necessidade, o resumo é muito sintético e não faz justiça à riqueza da abordagem. Ver: ALLEN, 2004; BOYER, 2005; HALL; THELEN, 2008; HALL, 2007; JACKSON; DEEG, 2006; JACKSON, 2007; THELEN, 2012.
} 
trabalho segmentadas. Esses elementos se articulam em instituições que se complementam e reforçam o padrão hierárquico de coordenação, dificultando a emergência de instituições horizontais e simétricas nos regimes produtivos latino-americanos.

Uma das maiores contribuições dessa literatura é mostrar que os obstáculos existentes para economias latino-americanas ingressarem em uma rota de desenvolvimento baseada na "nova economia", isso é, em setores que combinam tecnologia e serviços de alto valor agregado, tem suas raízes em complementaridades econômicas negativas, das quais é muito difícil escapar. Mesmo quando governos tentam reverter essa lógica, pressionados por demandas "anti-hierarquia", eles não conseguem alterar completamente os incentivos gerados pelas principais complementaridades do capitalismo hierárquico. É verdade que o aumento do investimento em educação e inovação oferece possíveis caminhos de escape. Contudo, falar de uma mudança para outro tipo de capitalismo é ainda prematuro (SCHNEIDER, 2013).

Para os propósitos deste trabalho, enfocaremos apenas a primeira das quatro dimensões que compõem o capitalismo hierárquico, qual seja, a concentração de empresas domésticas em um pequeno número de grupos econômicos diversificados.

De acordo com Colpan et al. (2010), grupos econômicos referem-se a um "mecanismo de coordenação econômica no qual empresas, legalmente independentes, utilizam-se de arranjos colaborativos para fortalecer seus ganhos econômicos" (p.17, tradução nossa). Colocado de forma simples, dentro de um grupo, companhias independentes não estão conectadas umas às outras por meio de relações de competição e rivalidade, nem por relações de controle em uma lógica de matriz e subsidiárias, mas por laços formais e informais que são caracterizados por uma lógica piramidal, diversificada e, na maioria dos casos, de propriedade familiar. De fato, essas três características - estrutura de propriedade e controle, diversificação do portfólio e característica dos proprietários - são apontadas, pela literatura, como os principais elementos que compõem um grupo econômico em economias em desenvolvimento (COLPAN et al 2010).

Em relação à primeira dimensão, estrutura de propriedade e controle, grupos econômicos assumem a forma de uma pirâmide, na qual uma empresa principal, no topo da hierarquia, possui participação acionária e controle de empresas legalmente independentes. Em estruturas piramidais, embora as empresas sejam legalmente independentes, elas estão subordinadas à empresa principal, em questões estratégicas e orçamentárias. Além disso, nesse modelo, é frequente a prática de emissão de ações sem direito a voto, o que possibilita a abertura de capital sem a transferência do controle da empresa. 
São muitas as implicações dessa estrutura, mas uma que tem alarmado os economistas é a discrepância entre os direitos sobre o fluxo de caixa e os direitos de controle, atribuídos aos acionistas minoritários (COLPAN et al. 2010) Essa discrepância permite que um acionista detentor de fração modesta dos direitos sobre o fluxo de caixa, exerça controle sobre a empresa piramidal, desproporcionalmente superior aos seus ativos, em função de sua participação acionária na empresa principal (holding). Uma consequência dessa forma de controle é a expropriação de acionistas minoritários pelos acionistas controladores que acabam por tomar decisões baseando-se nas demandas do grupo e não apenas de uma empresa. Nesse tipo de estrutura, há uma tendência para desviar o fluxo de caixa de uma empresa específica para investimentos e/ou gastos em outras empresas também participantes do grupo à custa dos acionistas minoritários (MORCK et al. 2005).

A segunda dimensão que caracteriza grupos econômicos é sua tendência para diversificação do portfólio em diferentes atividades produtivas. Mas, grupos econômicos variam na sua estratégia de diversificação. Basicamente, existem dois tipos: diversificação relacionada, quando empresas pertencentes a um grupo operam de forma integrada, com forte sinergia entre elas e diversificação não-relacionada, quando empresas atuam em diferentes indústrias não conectadas com a atividade central do grupo. Evidências apontam que grupos com escopo amplo e não relacionado de diversificação tendem a apresentar desempenho econômico inferior aos grupos com escopo mais focado em uma atividade central (DELIOS; MA, 2010; SCHNEIDER, 2009). Quanto mais diversificadas as atividades, maiores os empecilhos para a transferência de capacidades (capabilities) entre as empresas do grupo, tornando mais difícil a geração de incrementos (upgrades) tecnológicos.

Contudo, a maioria dos grupos econômicos latino-americanos encontra vantagens na estratégia de diversificação não-relacionada. De acordo com Schneider (2008), os maiores grupos econômicos da região atuam em, pelo menos, três setores diferentes. Essa estratégia é parte de uma rationale de mitigação de riscos, em que empresas optam por diversificação para reduzir as perdas oriundas de mudanças não previsíveis na lucratividade de um determinado setor, em decorrência da alta vulnerabilidade de economias emergentes. Além disso, grupos econômicos aproveitam de seu tamanho, capacidade financeira e estrutura organizacional para adquirir empresas existentes ou financiar a criação de novas empresas em resposta às oportunidades criadas por aumento dos preços de commodities ou mesmo por incentivos governamentais. O resultado é uma miríade de grupos econômicos diversificados que tendem a ser pouco eficientes em termos de escopo e escala. 
A terceira dimensão, diretamente conectada à estrutura de propriedade, diz respeito às características dos próprios acionistas controladores - quem são, quais as suas responsabilidades, e qual o seu poder de controle e influência dentro e fora do grupo. Em países de industrialização tardia, a maior parte dos grupos econômicos é controlada por famílias - seguida de controle estatal e estrangeiro (COLPAN et al. 2010). Em empresas familiares, seus membros detêm o controle estratégico e financeiro de todo o grupo, além de exercerem cargos na alta gerência, tanto nas empresas principais quanto nas empresas piramidais.

Para que consigam diversificar suas atividades, os proprietários últimos do grupo precisam ter capacidade de controle de todas as empresas, tendo em vista que a diversificação envolve, na maior parte das vezes, a canalização de fluxo de caixa de uma empresa para outra, afetando toda a pirâmide. De fato, decisões que envolvem a compra de novas empresas ou a entrada em novos setores podem implicar a aniquilação de alguma empresa do grupo ou, pelo menos, a desaceleração de seu plano de investimentos em prol da estratégia de todo o grupo. Assim, a estratégia de diversificação requer a concentração do controle nas mãos do proprietário, gerando um estilo de coordenação altamente hierárquico, dentro do grupo.

Tal princípio hierárquico torna-se ainda mais potencializado com o controle familiar. De fato, a diversificação torna-se mais lucrativa com a gestão familiar do que com a gestão profissional (Schneider 2013, p. 53). A possibilidade de apontar um familiar para gerenciar empresas do grupo assegura o controle do proprietário sobre o grupo, evitando que acionistas minoritários venham a interferir na estratégia. Além disso, tendo em vista que a diversificação não-relacionada dispensa uma coordenação avançada entre as empresas do grupo, as atividades de gerenciamento das firmas não demandam profissionais altamente qualificados; os incentivos para se contratar membros da família são maiores do que o contratar gerentes profissionais. Assim, ao mesmo tempo em que laços familiares possibilitam a maior concentração de poder nas mãos dos proprietários últimos do grupo, eles também facilitam a coordenação de transações básicas entre as firmas do grupo.

Essas três dimensões (pirâmide, diversificação não-relacionada e controle familiar) caracterizam o tipo dominante de grupo econômico encontrado no Brasil. Naturalmente, nem todos os grupos econômicos apresentam todas essas características ao mesmo tempo existem variações espaciais e temporais. Mas, o que unifica essas características é o fato de todas elas estarem baseadas em um princípio hierárquico que sustenta a autoridade de poucos sobre muitos, diferenciando, claramente, aqueles que ditam as regras e aqueles que seguem as regras, dentro do grupo. No Brasil, as grandes empresas privadas possuem algumas 
características adicionais: elas têm, em média, 50 anos de idade, concentram elevado nível de investimento estrangeiro e possuem vínculos corporativos com entidades governamentais (ALDRIGHI; POSTALI, 2010).

Em que medida essa forma de organização empresarial é boa ou ruim, para a promoção do desenvolvimento econômico, é um debate em aberto. Estudos comparativos de grupos econômicos têm ressaltado a habilidade dos chaebol coreanos, dos keireitsu japoneses e dos grupos escandinavos para investir em $\mathrm{P} \& \mathrm{D}$, contratar funcionários altamente qualificados $\mathrm{e}$ adicionar alto valor agregado à produção (COLPAN; HODBAY, 2010). Amsden (2001) chama atenção para algumas vantagens dos grupos econômicos a partir da experiência de sucesso do leste asiático: em situações de atraso e escassez de recursos, grupos econômicos conseguem mobilizar recursos necessários para industrialização, estabelecer canais de distribuição necessários à aquisição de matéria prima e escoamento da produção final, a custos altamente competitivos, pagando salários elevados para os trabalhadores qualificados, fortalecendo economias de escala e possibilitando o incremento tecnológico.

Em contraste, analistas observam que grupos econômicos latino-americanos têm enfrentado obstáculos para avançar na direção de uma economia mais intensiva em conhecimento, capaz de criar empregos de qualidade (COLPAN; HODBAY, 2010; DELIOS; MA, 2010; KHANNA; YAFEK, 2010; SCHNEIDER, 2009). Em sua tese sobre a modalidade hierárquica de capitalismo, prevalecente na América Latina, Schneider (2013) problematiza a presença de grupos econômicos e a conecta a alguns dos principais problemas observados na região, em especial, em relação à precariedade dos mercados corporativos e financeiros, à segmentação do mercado de trabalho e à baixa qualidade dos regimes de qualificação da mão de obra.

O argumento de Schneider (2013) é que a presença de grupos econômicos enfraquece as instituições necessárias para a coordenação das atividades produtivas que estão fora do âmbito dos grupos empresariais. Como consequência, as economias latino-americanas carecem de arranjos institucionais que suportem as demandas de setores industriais mais complexos, tais como mão de obra qualificada, capital e acesso à recursos tecnológicos. Não por acaso, essas economias sobressaem-se em setores que demandam níveis mais baixos de coordenação industrial, como na extração de recursos naturais e na produção de bens industriais de baixa intensidade tecnológica, como indústria têxtil e autopeças.

A exploração de recursos naturais é essencialmente um empreendimento para aqueles que possuem capital suficiente para esperar por retornos de longo prazo e resistir às instabilidades, já que os preços podem cair subitamente. Além disso, setores intensivos em 
capital demandam alto volume de recursos para iniciar um negócio, recursos que não podem ser canalizados por empresas de pequeno e médio porte. Por isso, grupos econômicos diversificados apresentam as melhores condições para engajamento nesses setores, especialmente, quando se deparam com commodities booms, situações nas quais investidores precisam mobilizar capital, em curto espaço de tempo, para se beneficiar da alta momentânea de preços.

Em contrapartida, setores intensivos em tecnologia e serviços de alto valor agregado tornam-se marginais no portfólio de investimentos dos grandes grupos econômicos, em razão dos riscos elevados (quando comparados aos setores tradicionais) e das condições de mercado (baixa competição e divisão de trabalho com empresas multinacionais que se especializam em setores intensivos em tecnologia). Considerando que grupos econômicos respondem por parcela significativa do PIB das economias latino-americanas, as atividades econômicas, exercidas por esses conglomerados, estão no cerne da inabilidade estrutural da região para gerar upgrade tecnológico.

Em síntese, segundo essa abordagem teórica, em economias de coordenação hierárquica, os obstáculos para a superação do atraso tecnológico têm suas raízes nas atividades conduzidas por grupos econômicos. A próxima seção propõe uma análise exploratória das dinâmicas relacionadas aos grupos econômicos a partir do caso brasileiro.

\section{CAPITALISMO HIERÁRQUICO E O BIG BUSINESS BIAS: O CASO BRASILEIRO}

A presença de instituições que contribuem para a manutenção de elevadas taxas de concentração de riqueza, em um pequeno rol de grandes empresas, e uma estrutura produtiva fortemente concentrada em bens de baixa intensidade tecnológica seria uma das principais características de economias de capitalismo hierárquico. A fim de verificar se essas instituições se fazem presente no capitalismo brasileiro, essa seção dedica-se à análise de três esferas institucionais que afetam diretamente o processo de geração de novas riquezas acesso a crédito e mercado de capitais, relações interfirmas e sistema de inovação.

A primeira dessas esferas seria a de acesso a crédito e mercado de capitais. Em uma economia de mercado, espera-se que a interação entre o setor produtivo e o setor financeiro seja orientada pelas expectativas de viabilidade econômica de um projeto industrial e suas possibilidades de retorno financeiro. Diante disto, o setor produtivo organiza-se para otimizar a sua capacidade de produção e, com isso, tornar-se mais atrativo para o setor financeiro. Já o 
setor financeiro organiza-se para otimizar suas condições de financiamento com maior margem de rendimento e, com isso, tornar-se mais atrativo para o setor produtivo. Com as reformas liberais e a liberalização financeira, esperava-se a otimização do mercado de crédito e de governança corporativa com a entrada de novos investidores privados, nacionais e estrangeiros.

A segunda esfera institucional que seria diretamente impactada em um contexto de economia de mercado diz respeito às relações entre firmas, em especial, às relações entre grandes empresas e micro e pequenas empresas emergentes. Com as reformas liberais e a privatização de empresas públicas, esperava-se que as firmas recém-privatizadas (bem como as demais firmas) buscassem otimizar sua capacidade produtiva por meio de estratégias como terceirização de algumas de suas atividades e melhoria de sua cadeia de fornecedores, estimulando o desenvolvimento de firmas de micro, pequeno e médio porte em toda economia. Com isso, as relações entre firmas tornar-se-iam mais complexas e competitivas.

Por fim, a terceira esfera institucional é o sistema de inovação, que se refere ao arcabouço jurídico, financeiro e científico, a partir do qual o setor produtivo investe no desenvolvimento tecnológico. Quanto maior a competição das empresas, maior o investimento delas por estratégias de diferenciação de seus produtos e por redução dos seus custos de produção. Por isso, em economias de mercado, espera-se que as empresas estejam constantemente inovando, mantendo-se, assim, competitivas. Com as reformas liberais e a abertura comercial, esperava-se que a entrada de produtos importados, tecnologicamente superiores aos produtos nacionais, assim como a instalação de empresas multinacionais, contribuísse para elevar o investimento das empresas brasileiras em desenvolvimento tecnológico, expandindo o sistema de inovação brasileiro.

\section{Acesso a crédito e mercado de capitais}

O acesso a crédito e a participação no mercado de capitais é um dos elementos mais importantes que sustentam o big business bias no capitalismo brasileiro. Segundo levantamento realizado pela Deloitte (2010) com empresas brasileiras de pequeno e médio porte mais bem sucedidas, a maioria delas (56\%) obteve recursos de fontes internas, a partir do reinvestimento de lucros. Um percentual significativo também obteve crédito por meio de financiamento bancário (46\%) e empréstimos de bancos de desenvolvimento (32\%).

Por outro lado, quando se olha para os índices relativos a fontes não bancárias, apenas $5 \%$ tiveram acesso a algum tipo de aporte por equity ou venture capital e apenas $1 \%$ 
participou do mercado de capitais. Embora a amostra seja pouco representativa, apenas das PMEs que atenderam aos critérios de bom desempenho econômico, esses resultados confirmam a preponderância do sistema bancário sobre o mercado de capitais no capitalismo brasileiro, já apontada por outros estudos (AMSDEN, 2001; GILSON; BLACK, 1998; KUMAR, 2005; LAZZARINI et al., 2011).

A preponderância do sistema bancário nas instituições de acesso a crédito não é exclusiva do capitalismo brasileiro: economias avançadas, como Alemanha e Japão, também dependem da figura dos bancos, tanto públicos quanto privados, para o financiamento de seus investimentos. A questão crucial - e que interessa diretamente a esse trabalho - é o ambiente institucional em que o sistema bancário está inserido. É sabido que firmas de pequeno e médio porte tendem a apresentar obstáculos estruturais para obter crédito bancário de longo prazo, em função da dificuldade de apresentação de garantias compatíveis, além da dificuldade de justificativa para a própria viabilidade econômica dos empreendimentos financiados (CLARK, DOLLAR, MICCO, 2004; LOVE e MYLENKO 2005; GALINDO e MICCO, 2007 apud ATERIDO; HALLWARD-DRIEMIER; PAGES, 2011).

No Brasil, a situação não é diferente e parece ainda mais agravada com a manifestação do big business bias, já que o acesso a crédito por PMEs tende a ser muito mais restrito do que para grandes negócios. Em pesquisa realizada por Felipe Zambaldi e outros (2011), envolvendo uma amostra de 65 mil PMEs, os autores confirmaram as dificuldades encontradas por essas firmas para acesso ao crédito, no país: “os resultados desse estudo reforçam a existência de uma quantidade elevada de segurança do financiador em contratos de empréstimo, e de que os negócios de pequeno porte enfrentam racionamento de crédito" (ZAMBALDI et al., 2011, p.313, tradução nossa) ${ }^{4}$

Em um estudo comparativo entre as economias emergentes dos BRICS (Brasil, Rússia, Índia, China e África do Sul), Estrin e Prevezer (2010) apontam que o Brasil possui os piores indicadores de acesso a financiamento por PMEs. ${ }^{5}$ Segundo dados apresentados pelos autores, embora o Brasil tenha a média mais alta de acesso a empréstimos bancários (35-75\%), grande parte dos empréstimos (percentual não indicado) é direcionada para firmas de grande porte (ESTRIN; PREVEZER, 2010).

\footnotetext{
${ }^{4}$ No original: The results of this study reinforce the existence of an optimal amount of collateral to lenders in a credit contract, and that small business borrowers face credit rationing

${ }^{5}$ Firmas brasileiras consideram o acesso a financiamento externo como o principal obstáculo para investir em seu próprio negócio. Mais da metade das firmas brasileiras que precisam de financiamento não solicitam crédito devido às taxas de juros elevadas e à complexidade dos requerimentos (Deloitte, 2010).
} 
Essa desvantagem pode ser ainda mais agravada pela presença de grupos econômicos. A começar, empresas pertencentes a grupos econômicos possuem a vantagem de conseguir mobilizar recursos dentro do próprio grupo, principalmente quando financiamentos de longo prazo são escassos e caros. Nesses casos, a escassez de crédito acaba por aumentar os retornos da concentração de recursos nas mãos de famílias abastadas. Ora, somente aqueles que possuem capacidade para alavancar grande volume de capital, a partir de fontes internas, incluindo recursos herdados e de investidores individuais, conseguem superar os altos custos transacionais, típicos de economias emergentes. Assim, empresas filiadas a grupos econômicos contam com canais de financiamento próprios, o que lhes permite sobreviver em mercados de capital subdesenvolvidos.

Segundo Amsden (2001), “no Brasil, por quarenta anos, 'nenhum investimento de relevância, envolvendo capital privado brasileiro, foi implementado sem o apoio do BNDES'. Não havia nenhuma fonte alternativa real de capital de longo prazo no Brasil a não ser o $B N D E S^{\prime \prime}$ (p.129, tradução nossa) ${ }^{6}$. De fato, o BNDES dirigiu o processo de formação de capital no país, provendo recursos para os principais grupos econômicos que participaram de projetos de infraestrutura, seja como produtores de bens de capital pesado, seja como prestadores de serviço de construção.

Com relação ao acesso a crédito não bancário, uma das razões para a baixa inserção de PMEs no mercado de capital está na própria estrutura piramidal dos grupos econômicos, conforme discutido na seção anterior, o que acaba por criar desincentivos para desenvolver mercados de capital que poderiam, potencialmente, beneficiar firmas de médio e menor porte (BECK; DEMIRGUCKUNT; MAKSIMOVIC, 2008). Isso porque, onde estruturas piramidais prevalecem, há um risco contínuo de expropriação dos acionistas minoritários pelo controlador majoritário.

Nessa situação, os custos das ações tendem a ser distorcidos, pois se espera que o prêmio compense o risco da expropriação. Com isso, empresas independentes dos grupos dificilmente conseguem oferecer um prêmio compatível com as expectativas de mercado e suas ações perdem competitividade. Ou seja, ao elevarem os riscos, grupos econômicos acabam por elevar os preços pagos no mercado de ações, excluindo aqueles que mais necessitam do acesso a capital (WOLFENZON; YEUNG; MORCK, 2005). Como

\footnotetext{
${ }^{6}$ No original: In Brazil, for forty years 'no major undertaking involving private Brazilian capital was implemented without BNDES support.' There was no real, alternative source for long-term capital in Brazil other than BNDES
} 
consequência, empresas de pequeno e médio porte tendem a ser alijadas dos mercados de capital.

É importante destacar que, em comparação com as principais economias latinoamericanas, o Brasil tem mantido posição de liderança no número de firmas listadas no mercado de capitais, embora se encontre ainda muito aquém do Chile no quesito valor das ações negociadas na bolsa em relação ao PIB.

Gráfico I - Número de firmas domésticas listadas no mercado de capitais

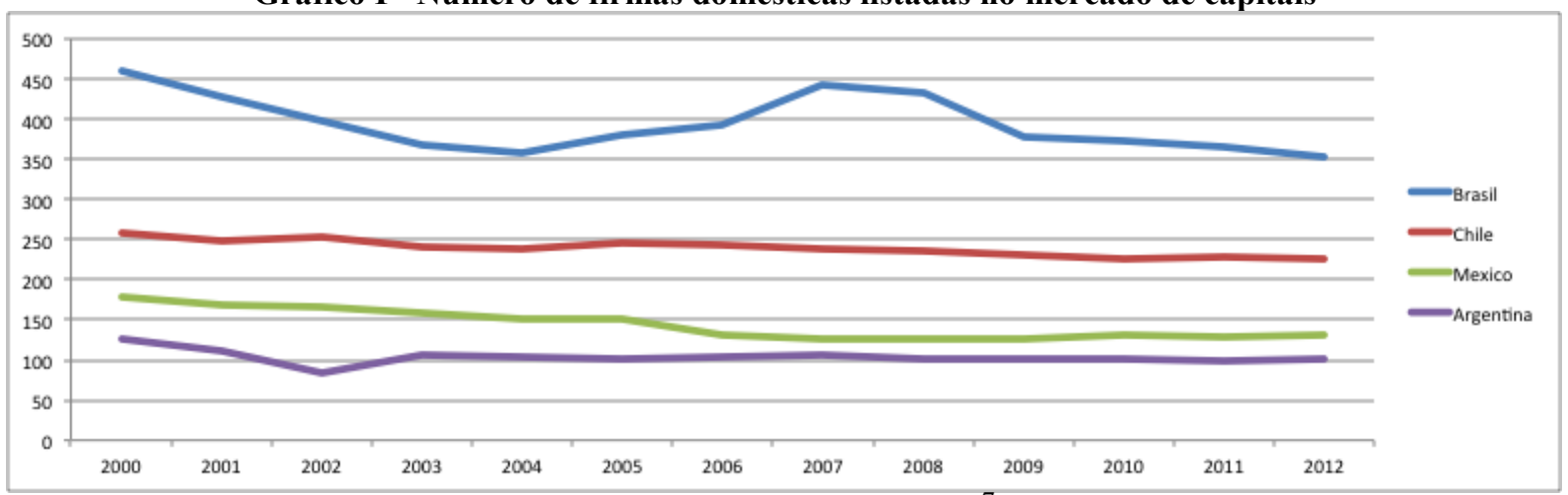

Fonte: Elaboração própria a partir de dados do World Bank Data, $2013^{7}$

Gráfico II - Percentual da capitalização de mercado (preço das ações) em relação ao PIB

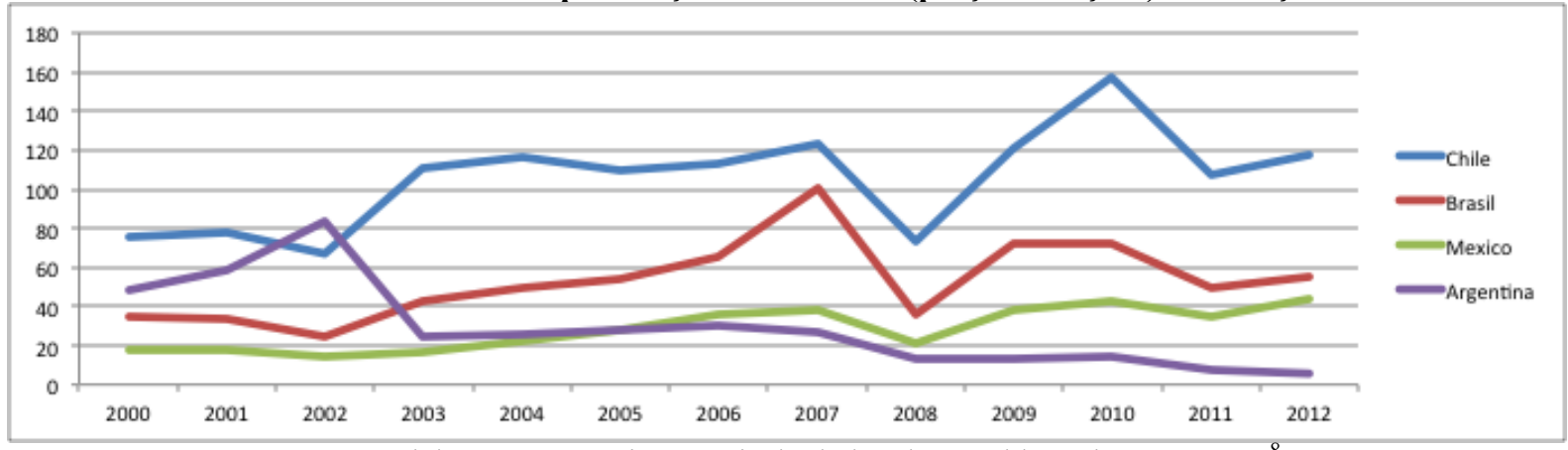

Fonte: Elaboração própria a partir de dados do World Bank Data, $2013^{8}$

É verdade que o Brasil experimentou crescimento vigoroso do mercado de capitais nos últimos 10 anos, passando de 63\% do PIB, em 2003, para 119\% do PIB, em 2012 (CVM, 2013). Tal destaque deve-se não somente à maior estabilidade econômica, alcançada pelo país desde fins dos anos 90, mas, sobretudo, à introdução de padrões mais fortes de governança corporativa. Desde os anos 2000, o mercado de capitais brasileiro conta com três

7 Disponível em:

http://data.worldbank.org/indicator/CM.MKT.LDOM.NO/countries?page=2\&display=default, acesso em 31 de julho de 2014.

8 Disponível em:

http://data.worldbank.org/indicator/CM.MKT.LCAP.GD.ZS/countries?display=default, acesso em 31 de julho de 2014. 
níveis de governança, sendo o Novo Mercado ${ }^{9}$ aquele que apresenta o maior grau de controle e transparência.

As regras do Novo Mercado foram introduzidas para aumentar a proteção do acionista, especialmente o minoritário, com vistas a fortalecer a competitividade, reduzir o papel controlador do estado, diversificar as fontes de financiamento de longo prazo, encorajar a aquisição minoritária e enfraquecer os tradicionais monopólios. A criação de um segmento especial, o Novo Mercado, tinha em vista, justamente, oferecer uma categoria atraente para as empresas, conferindo maior credibilidade ao mercado de capitais brasileiro e, ao mesmo tempo, possibilitando a atração de novos investidores, sobretudo estrangeiros.

Contudo, o Novo Mercado não se mostrou uma alternativa, nem para grandes empresas, vinculadas a grupos econômicos, nem para PMEs. Ao contrário, grande parte das empresas brasileiras, filiadas a grupos econômicos, não aderiu ao Novo Mercado e manteve um importante artifício que lhe permite a emissão de ações, sem direito a voto, também conhecidas como ações preferenciais, por meio das quais é possível obter recursos sem a perda de controle corporativo.

O exame de estatísticas descritivas da amostra revela que empresas com estrutura piramidal de propriedade (EPP) apresentam uma fração do capital, na forma de ações sem direito a voto, significativamente maior do que a das empresas sem EPP. Das empresas com EPP, 33\% tinham ações sem direito a voto em proporção inferior a $10 \%$ do capital social, enquanto $31 \%$ haviam emitido mais de $60 \%$ do capital na forma dessa classe de ações - aproximando-se, portanto, do limite de 66.6\%, imposto pela Lei das S.A. (ALDRIGHI e POSTALI, 2011, p. 29).

A não adesão de grupos econômicos ao Novo Mercado revela as dificuldades para criação de mercados de capitais mais dinâmicos em ambientes hierárquicos. Mesmo novos desenhos institucionais não foram suficientes para alterar a distribuição do controle corporativo entre as firmas listadas: os altos níveis de concentração corporativa persistem, como atestado pela literatura de governança corporativa no Brasil (AGUILERA et al., 2011; ALDRIGHI; ANTONIO; POSTALI, 2011; ALDRIGHI; POSTALI, 2010; LAZZARINI et al., 2011). Ao mesmo tempo, no que diz respeito à inclusão de PMEs no mercado de capitais, pouco se avançou. O Novo Mercado ainda é uma realidade muito distante para PMEs, pois os

9 Implantado, em dezembro de 2000, pela Bolsa de Valores de São Paulo (BOVESPA), o Novo Mercado é um segmentos especial de listagem, desenvolvido com o objetivo de proporcionar ambiente de negociação mais atrativo para os investidores. Nesse segmento, as empresas registradas assumem compromissos de governança em adição aos existentes na legislação, compromissos esses relacionados à prestação de informações que facilitam o acompanhamento e a fiscalização dos atos da administração e dos controladores da companhia; e à adoção de regras societárias que melhor equilibram os direitos de todos os acionistas, independentemente da sua condição de controlador ou investidor. Fonte: http://www.comptoirdescotonniers.com/eboutique/tous-noslooks?page=all, acessado em 21 de julho de 2014 . 
custos para ser alcançado o nível de governança, exigidos por esse segmento, não é compensado pelos ganhos obtidos na bolsa de valores.

Com o objetivo de alavancar maior participação de PMEs no mercado de capitais brasileiro, foi lançado, em 2004, o "BovespaMais", um nível de admissão inspirado no Novo Mercado, mas com regras mais flexíveis para PMEs (ALDRIGHI, 2008; SCHAPIRO, 2009). Até 2013, apenas três empresas haviam sido listadas nessa categoria, revelando um crescimento aquém do esperado para o segmento. ${ }^{10}$ Portanto, embora o mercado de capitais brasileiro tenha evoluído consideravelmente, para os padrões latino-americanos, ele ainda não atingiu o nível de maturidade encontrado em outras economias emergentes, principalmente no que diz respeito à inclusão financeira das PMEs.

Uma alternativa ao mercado de capitais é o acesso a fontes de financiamento via private equity e venture capital. Mercados emergentes, como Brasil, têm-se destacado progressivamente no aumento do volume de investimentos de private equity, mas ainda encontram-se em patamares abaixo do observado nos Estados Unidos e Europa Ocidental (EMPEA, 2014). Dentre os BRICS, China e Índia lideram o ranking de volume e número de operações envolvendo private equity, apresentando um histórico muito superior ao observado no Brasil e Rússia (PREQIN, 2013).

Mas, embora o Brasil apresente a menor taxa de confiança em private equity (3-4\%) dentre os BRICS (ESTRIN; PREVEZER, 2010), o estudo da Deloitte aponta que as PMEs brasileiras parecem estar atentas ao crescimento do número de participações de fundos de private equity. Para os próximos dois anos, espera-se um aumento de quase $10 \%$ no número de PMES que utilizam esse tipo de financiamento (Deloitte, 2013). De fato, segundo relatório da PriceWC, o número de transações envolvendo fundos de private equity tem aumentado significativamente e registrou recorde da série histórica, em 2013, com 380 operações.

10 No final de 2013, a CVM anunciou novas reformas que seriam implantadas ao longo de 2014 para possibilitar maior inclusão de PMEs no mercado de capitais. O conteúdo dessas reformas, bem como seus resultados fogem o escopo desse trabalho. 
Gráfico III- Evolução do número de participações em Private Equity - Brasil (Período 2007-2013)

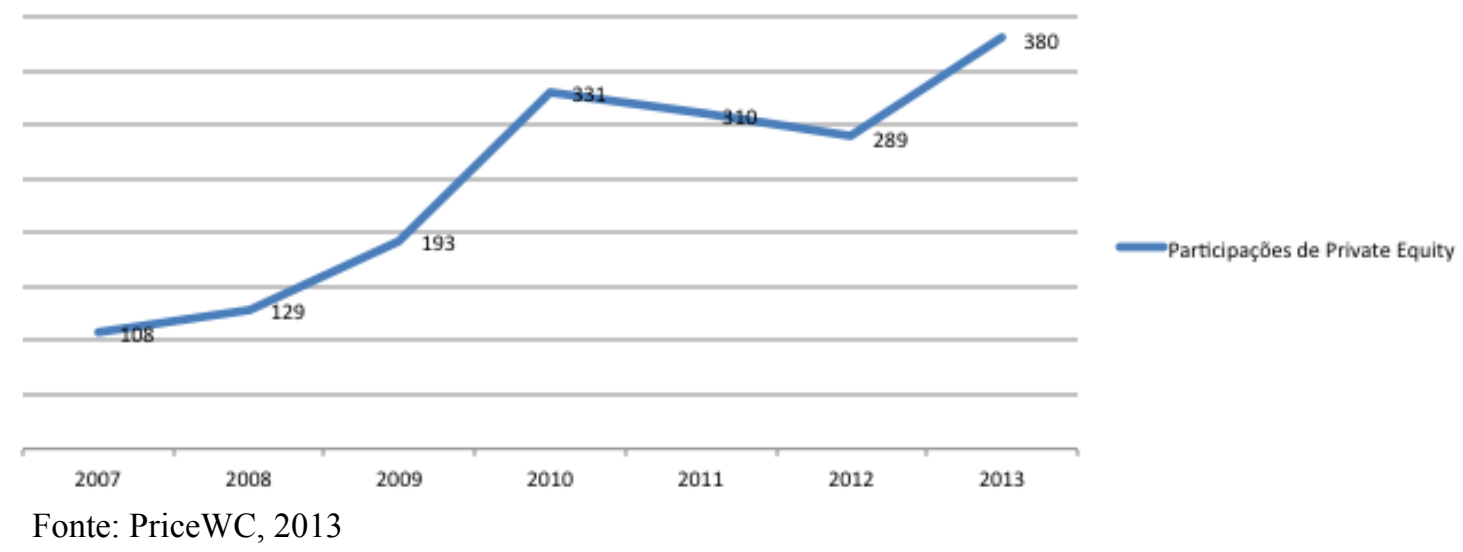

Com relação ao número de operações envolvendo venture capital, também observa-se tendência de crescimento. Segundo relatório da KPMG, entre 2011 e 2013, houve crescimento de $58 \%$ do capital comprometido para operações de venture capital no país (KPMG, 2014). Contudo, a evolução de financiamentos envolvendo venture capital que beneficiem especialmente PMEs parece encontrar um limite que dificilmente será superado a curto prazo. Conforme argumenta Olin et al (1999), a indústria de venture capital só consegue florescer quando a saída via oferta pública inicial (IPO, de initial public offering) é uma opção factível tanto para o empreendedor quanto para o investidor:

Nós argumentamos que não é uma coincidência - que venture capital floresce especialmente - e talvez somente se - o investidor em venture capital possa sair de uma empresa bem sucedida de seu portfólio por meio de uma oferta publica inicial (IPO), o que requer um mercado de capitais ativo. (OLIN; GILSON; BLACK, 1999, p.1, tradução nossa) ${ }^{11}$

Levando-se em consideração o argumento de Olin et al (1999), para quem um mercado vibrante de venture capital requer um mercado de capitais bem desenvolvido, observa-se a existência de relações de complementaridade negativas que têm por base a estrutura piramidal de grupos econômicos: grupos econômicos criam desincentivos para inclusão de PMEs, no mercado de capitais, o que, por sua vez, diminui as possibilidades de saída para investidores de venture capital, inibindo o desenvolvimento desse mercado. Ou seja, indiretamente, a presença de grupos econômicos cria desincentivos para a aplicação de regras mais incisivas de proteção aos direitos de propriedade, o que, por sua vez, aumenta o gap entre empresas grandes e PMEs, no acesso a crédito.

\footnotetext{
${ }^{11}$ No original: We argue here that this is no accident -- that venture capital can flourish especially -- and perhaps only -- if the venture capitalist can exit from a successful portfolio company through an initial public offering (IPO), which requires an active stock market.
} 


\section{Sistemas de Inovação}

Um dos obstáculos estruturais das economias médias está na capacidade de gerar inovação. No Brasil, observa-se uma correlação positiva entre tamanho da firma e capacidade de gerar inovação. Segundo pesquisa realizada pelo IBGE (PINTEC, 2013), a taxa de inovação em produtos e processos para empresas, no setor industrial de pequeno porte (10 a 49 pessoas ocupadas), é de $34 \%$ contra $56 \%$ de empresas de maior porte (acima de 500 funcionários). A pesquisa também revela que a média de dispêndio em inovação das empresas industriais de grande porte que relataram ter implementado algum tipo de atividade inovativa é, significativamente, maior que a média de dispêndios de empresas de pequeno porte (R \$29 milhões por empresa contra $\mathrm{R} \$ 210$ mil, respectivamente). O maior volume de recursos destinados a atividades inovativas é certamente um fator que favorece a capacidade de inovação das empresas de grande porte.

Contudo, quando se observa a relação entre o valor investido em inovação e a receita líquida de vendas de produtos e serviços, anota-se que empresas industriais de menor porte investem, significativamente, mais que empresas de grande porte $(4,6 \%$ contra $2,0 \%$, respectivamente). Mas, ainda que, o investimento seja proporcionalmente maior, empresas de pequeno porte apresentam mais dificuldade para acessar redes institucionais de pesquisa do que empresas de grande porte.

O gráfico 4 ilustra a enorme desigualdade no acesso a redes de cooperação para inovação: na indústria, 88\% das empresas de pequeno porte (10-29 pessoas ocupadas) que implementaram algum tipo de inovação não contavam com qualquer tipo de relação institucional com terceiros, ao passo que 49\% das empresas de grande porte que implementaram inovação mantinham algum tipo de parceria, seja com clientes ou consumidores, instituições de testes, ensaios e certificações, fornecedores, universidades e centros de pesquisa, empresas de consultoria, centros de capacitação profissional, empresas do grupo e, até mesmo, com concorrentes. 
Gráfico IV - Acesso a redes institucionais de inovação por porte de empresa

Período 2009-2011

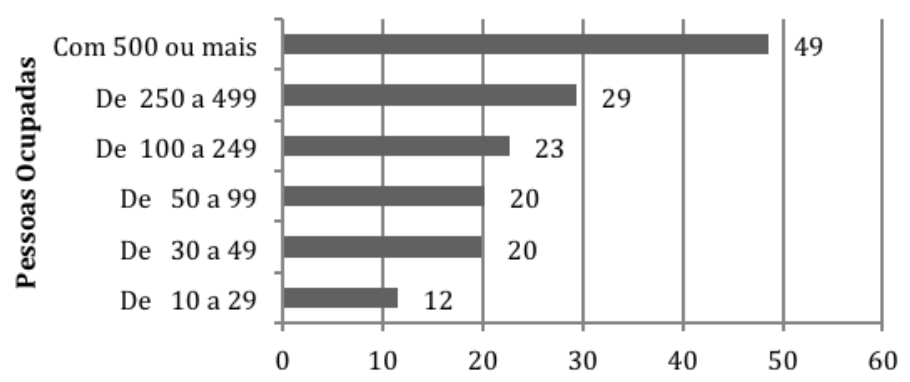

- \% de Empresas Industriais que cooperam com outras instituições

Fonte: PINTEC, 2013

Outro fator que explica a correlação positiva entre taxa de inovação e porte da empresa diz respeito à capacidade para contratação de mão de obra qualificada para conduzir atividades inovativas. Enquanto a média de graduados ocupados em atividades internas de Pesquisa e Desenvolvimento nas empresas de grande porte, é de 24 profissionais, por empresa, esse valor é de apenas 0,19 em empresas de pequeno porte (10 a 29 pessoas ocupadas), conforme demonstrado na tabela 1.

\begin{tabular}{|c|c|c|c|c|}
\hline & Indústrias extrativas e de transformação & Relação pós-graduado/empresa & Relação Graduado/Empresa & Relação Nivel Médio-Fundamental/Empresa \\
\hline De & 10 a 29 & 0.03 & 0.19 & 0.10 \\
\hline De & 30 a 49 & 0.02 & 0.26 & 0.10 \\
\hline & 50 a 99 & 0.04 & 0.42 & 0.18 \\
\hline & 100 a 249 & 0.18 & 1.43 & 1.32 \\
\hline De & 250 a 499 & 0.37 & 2.46 & 1.17 \\
\hline Con & m 500 ou mais & 3.41 & 24.81 & 7.51 \\
\hline
\end{tabular}

Apesar de empresas de menor porte ter maior dificuldade para mobilizar recursos financeiros e materiais, elas se beneficiam relativamente menos dos programas governamentais de apoio à inovação. Mais uma vez, a proporção de empresas inovadoras que utilizaram programas do governo cresce com o tamanho da empresa: na indústria, 33,4\% das que ocupam entre 10 e 99 pessoas, 40,4\% daquelas que possuem entre 100 e 499 pessoas ocupadas e atinge $54,8 \%$ nas empresas com 500 ou mais pessoas ocupadas. Dentre os tipos de apoio praticamente exclusivos de empresas de maior porte (acima de 100 pessoas ocupadas), destacam-se os projetos de inovação em parcerias com universidades, as subvenções econômicas à $\mathrm{P} \& \mathrm{D}$ e à inserção de pesquisadores, e a Lei de $\mathrm{P} \& \mathrm{D}$ e inovação tecnológica (Lei no 11.196, de 21.11.2005). 


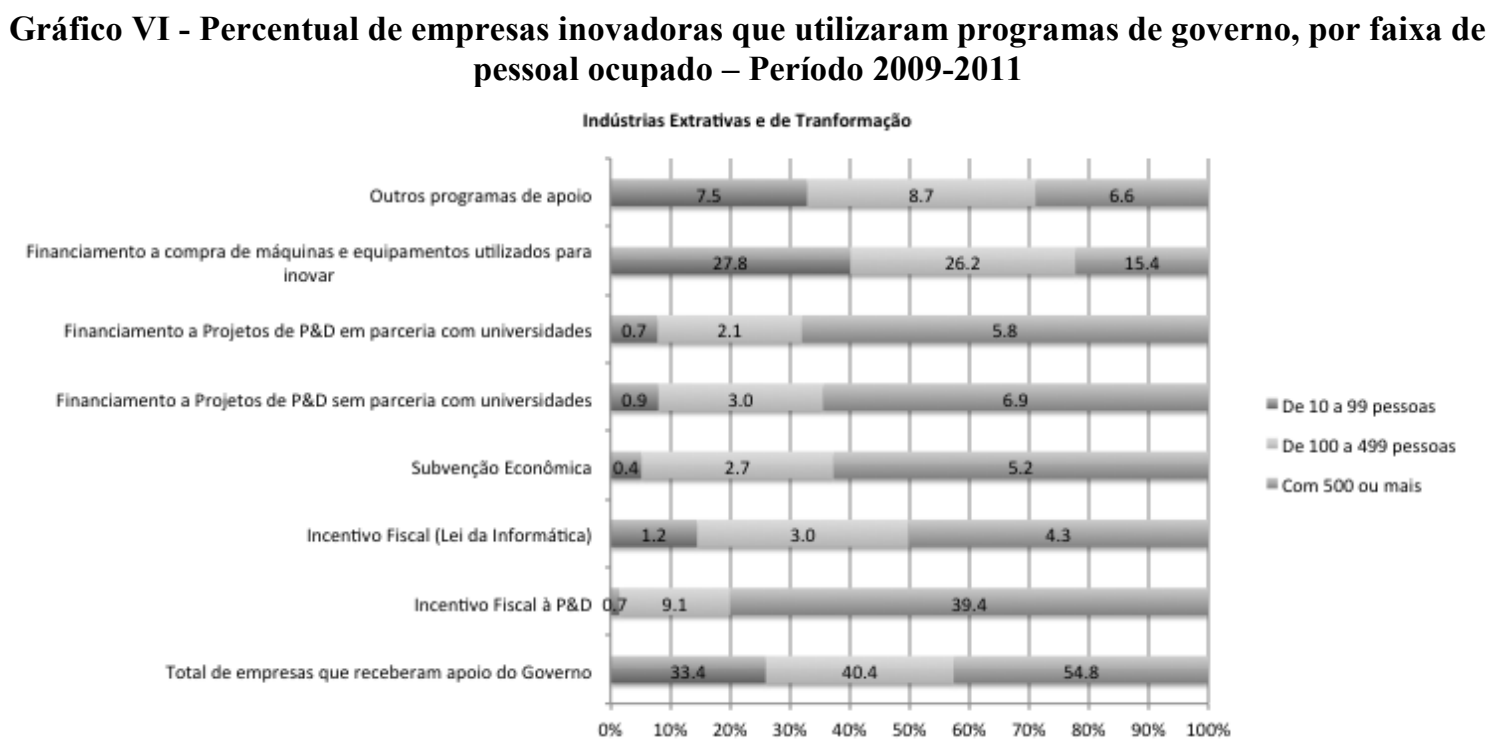

Fonte: PINTEC, 2013

Assim, não somente a maior capacidade para mobilizar recursos financeiros e materiais, mas, também, o acesso a redes institucionais de pesquisa, capacidade para contratar mão de obra qualificada e dedicada a atividades de pesquisa e desenvolvimento e facilidade de captação de apoio governamental ajudam a compreender o big business bias, no sistema de inovação, no Brasil.

\section{Relações de cooperação inter-firmas}

Enquanto o big business bias manifesta-se nos regimes de crédito e de inovação, o mesmo não é tão óbvio nas relações de cooperação interfirma. Em ambientes hierárquicos, grupos econômicos podem prover diferentes tipos de oportunidades para firmas de pequeno e médio porte que atuam como fornecedores em cadeias produtivas verticais. Esse tipo de interação vertical pode aumentar o volume de bens demandados às PMEs ao mesmo tempo em que estimula o upgrade tecnológico.

A pesquisa Deloitte (2010) revelou que, aproximadamente, 50\% das PMEs consideradas "bem-sucedidas" participaram de cadeias produtivas verticais, atuando como fornecedores de produtos ou prestadores de serviços customizados para as grandes corporações. O mesmo estudo revelou que grandes empresas são importantes clientes das médias empresas, representando $34 \%$ de sua receita (embora elas representem apenas $1 \%$ do número total de clientes). ${ }^{12}$ As médias empresas que mantêm relações comerciais com $40 \%$ of SME's revenues, followed by other enterprises (35\%), consumers (14\%) and governments $(12 \%)$. 
grandes empresas avaliaram essa interação positivamente: aumenta os padrões de qualidade e estimula PMEs a se tornarem mais eficientes, expande o portfólio de cliente das médias empresas, abre novas fontes de financiamento.

Porém, grandes empresas são clientes "complicados". Empresas de maior porte, normalmente, exigem certificações específicas e demandam alguns procedimentos burocráticos para a seleção e contratação de seus fornecedores. Entrar na cadeia de suprimento de um grande conglomerado requer boa dose de negociação e conhecimento tácito para lidar com as exigências. De acordo com a Deloitte (2010), as exigências mais comuns, feitas pelas grandes empresas, são: Selos de gestão de qualidade (ISO 9000 etc), Customização e adequação dos produtos e/ou serviços e Certificações socioambientais (ISO 14000, SA 8000 etc). Assim, ter acesso a grandes companhias pode ser bastante complexo, restringindo o leque de PMEs elegíveis para se tornar fornecedor de grandes empresas.

Além disso, relações comerciais com grandes empresas podem ser bastante instáveis. Como a capacidade de negociação delas é muito superior à das PMEs, grandes corporações podem impor a margem de preço que estão dispostas a pagar. Elas podem quebrar contatos e mudar de fornecedor, sem grandes constrangimentos. Tal instabilidade pode ser fatal para a sobrevivência e lucratividade de PMEs. Não é por acaso que cerca de $50 \%$ das médias empresas avaliaram a dependência de grandes corporações como algo muito arriscado (DELOITTE, 2010). Assim, enquanto tornar-se fornecedor de uma grande corporação pode levar ao sucesso, as chances de entrar nesse mercado são muito restritas. Uma vez fornecedor, relações duradouras com grandes empresas podem ser muito lucrativas, mas também muito instáveis.

Outra opção para PMEs é vender seus ativos para grandes empresas, por meio de operações de fusão e aquisição (F\&A). De fato, esse tipo de operação tem, gradualmente, crescido no Brasil, já que, cada vez mais, PMEs vêem F\&As como uma boa oportunidade para alcançar novos mercados (DELOITTE, 2010). De acordo com a PricewaterhouseCoopers, o número de operações de M\&A envolvendo PMEs brasileiras, especialmente no setor de TI, excedeu as expectativas para 2013 (VALOR, 2013). ${ }^{13} \mathrm{O}$ aumento do número de F\&As, no Brasil, sinaliza uma importante preocupação das PMEs: permanecer pequeno pode ser muito arriscado, especialmente em momentos de crise. Assim, na medida em que PMEs começam a ver suas possibilidades de crescimento limitadas, F\&A tornam-se mais atrativas.

13 Fonte: http://www.valor.com.br/empresas/3379968/no-brasil-maior-interesse-e-por-fusoes-e-aquisicoes 
Médias empresas podem também tornar-se competidores de grupos econômicos: $37 \%$ das PMEs que compõem a amostra competem com empresas de maior porte e 49\% esperam competir nos próximos 3 a 5 anos em, pelo menos, um segmento (Deloitte, 2010). O estudo, contudo, não fornece detalhes sobre em quais circunstâncias PMEs competem com grandes empresas. A forma como grandes empresas estão organizadas - sob a forma de grupos econômicos - pode comprometer a competição livre de mercado. Firmas pertencentes a grupos econômicos estão em posição vantajosa para mobilizar recursos dentro do grupo e mesmo para estabelecer parcerias com outras firmas com o objetivo de tornarem-se mais competitivas e assegurar recursos para derrubar a concorrência.

Além disso, como observado por Sergio Lazzarini (2011), os grupos econômicos nacionais estão todos conectados por meio de redes de propriedade, nas quais um grupo pequeno de proprietários últimos conecta diferentes grupos. Baseado em uma base de dados de 640 empresas brasileiras, de 1995 a 2003, Lazzarini observa que as redes existentes entre proprietários que compartilham a propriedade de uma mesma companhia apresentam as características de um "mundo pequeno". ${ }^{14}$ Em um "mundo pequeno", a distância entre dois pontos da rede é pequena em função do número de conexões que, indiretamente, unem os pontos. Nesse sentido, as firmas brasileiras estão ligadas umas às outras, seja por participarem do mesmo grupo, seja por apresentarem intermediários que vinculam diferentes grupos.

As implicações desse padrão de rede são muitas. Por um lado, a aglomeração entre proprietários últimos, incluindo agências governamentais, facilita a coordenação para projetos de grande volume. Por outro lado, firmas conectadas podem usar de seus laços para extrair benefícios privados, não disponíveis aos empreendedores menos conectados, sem mencionar a possibilidade de formação de cartéis e outros acordos de preço. Nesse sentido, o pequeno mundo de grandes negócios reforça o padrão hierárquico de coordenação, por facilitar a formação de laços de solidariedade entre firmas pertencentes a diferentes grupos e aumentar a distância com aquelas que não fazem parte das redes de propriedade.

Este controle concentrado também pode levar a preocupações na governança corporativa. Mas,
mais importante, confiar a governança de enormes fatias do setor corporativo de um país a uma
pequena elite pode enviesar a alocação de capital, retardar o desenvolvimento do mercado de
capitais, obstruir a entrada de empreendedores outsiders, e retardar o crescimento. Além disso,
com o objetivo de preservar suas posições privilegiadas sob o status quo, tais elites acabam
investindo em conexões políticas que inibem o desenvolvimento institucional dos mercados de

$14 \mathrm{O}$ termo "mundo pequeno" diz respeito a redes com pequeno diâmetro e curta distância entre seus pontos. O termo ficou conhecido pela famosa formulação de John Gaure, em 1929, sobre "os seis graus de separação" entre qualquer individuo (JACKSON, 2008, p. 86). 
capitais e criam uma variedade de barreiras de entrada. Essas implicações econômicas abrangentes podem ser muito sérias (WOLFENZON et al., 2005, p.657, tradução nossa) ${ }^{15}$.

Portanto, relações interfirmas, em mercados hierárquicos, tendem a ser segmentadas: grupos econômicos são altamente integrados, ao passo que PMEs são excluídas, não somente do universo dos grupos econômicos como, também, das redes de propriedade. Grandes empresas e PMEs são conectadas somente por vínculos verticais, em cadeias de suprimentos, o que reforça a assimetria e entre ambos.

\section{O AMBIENTE DE NEGÓCIOS NA INDÚSTRIA BRASILEIRA}

A vantagem de grandes negócios para conduzir as atividades econômicas em que o Brasil dispõe de maiores vantagens comparativas - indústrias extrativas e indústria de capital - engendra uma dinâmica de exclusão que se soma à lógica hierárquica dos grupos econômicos, dinâmica essa aqui referenciada como big business bias. Nas esferas institucionais analisadas - acesso a crédito e mercado de capitais; sistema de inovação; relações interfirmas - foi possível identificar que o ambiente de negócios brasileiro é permeado por mecanismos hierárquicos que não somente tornam mais difícil a coordenação de mercado, como também podem, sistematicamente, excluir ou prover acesso desigual a determinados recursos para pequenas e médias empresas, reduzindo as oportunidades para aqueles que não fazem parte de grupos econômicos.

Mecanismos hierárquicos são fortalecidos por barreiras naturais de entrada, dado o caráter da própria atividade econômica, conduzida por grupos econômicos, majoritariamente em setores que demandam alto volume de investimento (extração de commodities minerais, por exemplo). Mas, mesmo em setores em que esse tipo de barreira não se faz presente, mecanismos hierárquicos podem ser ativados por meio de barreiras institucionais que, direta ou indiretamente, são sustentadas pelos grupos econômicos. Essas barreiras podem ter caráter formal, criadas pelas próprias instituições públicas (regulações, tarifas, crédito, etc) ou informal, alimentadas por redes de relacionamento entre proprietários. Tais barreiras não

\footnotetext{
${ }^{15}$ No original: This concentrated control can lead to corporate governance concerns - a range of agency problems. But, more importantly, entrusting the governance of huge slices of a country's corporate sector to a tiny elite can bias capital allocation, retard capital market development, obstruct entry by out- sider entrepreneurs, and retard growth. Furthermore, to preserve their privileged positions under the status quo, such elites might invest in political connections to stymie the institutional development of capital markets and to erect a variety of entry barriers. These economy wide implications can be most serious.
} 
somente podem restringir a entrada de novas empresas, mas, principalmente, inibir a operação e o crescimento dos negócios existentes.

Assim, uma das principais implicações do big business bias observado no capitalismo brasileiro, estaria na ativação de barreiras institucionais de entrada que inibem a criação de novas riquezas. De fato, estudos em economia política apontam barreiras institucionais de entrada como um dos principais entraves ao crescimento econômico. ${ }^{16}$ Segundo North e Thomas (1973), barreiras de entrada restringem o desenvolvimento, pois alimentam o monopólio de determinados grupos que perderiam sua vantagem econômica caso novos arranjos produtivos pudessem ser adotados. ${ }^{17}$

Adam Przeworski (2007) aponta para uma correlação entre extensão de direitos políticos, redução de barreiras de entrada e crescimento econômico. Segundo o autor, enquanto os direitos políticos eram altamente restritos, os segmentos econômicos mais abastados conseguiam assegurar seu direito à propriedade por meio de barreiras legais que impediam o acesso a títulos proprietários. Mas, no momento em que a classe média adquiria direitos políticos, tais barreiras legais foram gradualmente desmanteladas, o que levou a uma maior redistribuição de riquezas e à aceleração do crescimento econômico.

Contudo, Przeworski (2007) observa que após a implementação completa do sufrágio universal, tem-se uma nova onda de desaceleração do crescimento econômico, agora causada pela criação de novos tipos de barreiras, não mais legais, mas que continuam a proteger os incumbentes, restringindo a entrada de empreendedores, a mobilidade de trabalho, o acesso ao crédito e a novas tecnologias. ${ }^{18} \mathrm{Ou}$ seja, mesmo em economias avançadas, observa-se uma tendência de criação de novas barreiras de entrada, uma vez que a extensão de direitos políticos chega a um certo equilíbrio. ${ }^{19}$

Mas, em países em desenvolvimento, observações empíricas sugerem que as barreiras de entrada não somente são mais elevadas, como o são mais densas e mais complexas

16 Ve: Parente and Prescott 2000, Djankov et al. 2002, Rajan and Zingales 2003, Acemoglu, Aghion, and Zilibotti 2004, Comin and Hobjin 2004, Llavador and Oxoby 2005, Acemoglu 2005, 2007, Rajan 2007

17 North e Thomas (1973) argumentam que barreiras de entrada previnem o desenvolvimento, pois eles asseguram o monopólio de grupos de indivíduos que perderiam recursos se novas tecnologias e novos arranjos produtivos fossem adotados (HERRENDORF; TEIXEIRA, 2011).

18 A tese de Przeworski é que em sociedades desiguais, democracia não é suficiente para promover redistribuição, pois a elite econômica acaba criando novas barreiras de entrada. Ele propõe que o debate sobre "redistribuição" deixe de lado políticas fiscais e passe a pensar em mecanismos de equalização das capacidades de geração de riqueza.

19 Acemoglu, Aghion, and Zilibotti (2004) analisam um equilíbrio no qual capitalistas subornam os políticos para manter políticas anti-competitivas. 
(ACEMOGLU; JOHNSON; ROBINSON, 2005; MAHONEY, 2010). ${ }^{20}$ Em contextos de elevada desigualdade econômica, como no Brasil, a abertura política tende a ser acompanhada pela ativação de mecanismos para a proteção da renda e dos direitos de propriedade da elite econômica, contrabalanceando os impulsos redistributivas alimentados pela democracia (ANSELL e SAMUELS, 2014). Nesse sentido, a criação de novas riquezas depende não apenas de condições econômicas propriamente ditas, mas de um contexto políticoinstitucional favorável à emergência de novos atores econômicos.

Não é por acaso que o apoio ao empreendedorismo e ao desenvolvimento de pequenas e médias empresas tornou-se o alvo das políticas de fomento econômico de agências internacionais de desenvolvimento, como do Banco Mundial e BID. A premissa básica dessa estratégia é justamente possibilitar o acesso a novas riquezas por um maior número de pessoas, em uma espécie de democratização de acesso ao mercado. Ora, mercados hierárquicos dificultam essa democratização de acesso na medida em que criam um ambiente de negócios que, sistematicamente, desfavorece aqueles que estão na base da pirâmide e reforçam o privilégio dos que estão no topo.

Preocupado com os entraves trazidos pela complexidade institucional e pelos custos de processos regulatórios, o Banco Mundial lançou, em 2003, uma série anual de monitoramento do ambiente de negócios, em 185 países, denominado Doing Business. O relatório abrange dois tipos de indicadores: os relacionados à força das instituições legais relevantes para a regulação de negócios e os relacionados à complexidade e custos dos processos necessários para a abertura, funcionamento e fechamento de empresas. O principal achado da primeira edição do estudo foi que economias de baixa renda possuem ambiente de negócios muito mais complexos e truncados do que economias avançadas. Desde então, os padrões encontrados em países desenvolvidos passaram a ser utilizados como referência para o progresso das economias menos avançadas.

De acordo com o relatório Doing Business, o Brasil mantém, há aproximadamente 10 anos, o mesmo patamar no ranking mundial de ambiente de negócios, sendo que, em 2013, ocupava a $130^{\mathrm{a}}$ posição. Aliás, o país teve um dos piores progressos, na América Latina, perdendo apenas para Venezuela, Antigua e Barbuda, Suriname e St. Lucia. Considerando o indicador "progresso em reduzir a distância em relação à economia mais eficiente", entre

20 Ver também: Bartelsman et al. (2004), Djankov et al. (2002), Fisman and Sarria-Allende (2004), Eslava et al. (2004), Fajnzylber et al. (2001), Klapper et al. (2004), Pavcnik (2002), Roberts (1996a, 1996b) e World Bank (2004). 
2005-2013, a média latino-americana foi de 3.9, ao passo que o Brasil evoluiu apenas 0.6 pontos.

Essa baixa variação, quando comparada aos demais países latino-americanos, reflete uma dificuldade estrutural observada no país, para favorecer o crescimento e a estabilidade de novos empreendimentos. Um dos principais indicadores de entrada diz respeito ao tempo, número de processos, custos e capital mínimo necessário para se iniciar um negócio. Segundo o relatório Doing Business do Banco Mundial, o Brasil ocupa o $121^{\circ}$ lugar no ranking mundial no quesito "facilidade para se abrir um novo negócio" (2013).

Somam-se a esses obstáculos de entrada, outras barreiras que dificultam o crescimento de novos negócios: elevada carga tributária, dispêndio realizado para a administração do pagamento de tributos $^{21}$, dificuldade de acesso a crédito, baixo acesso à mão de obra qualificada, rigidez das legislações trabalhistas e concorrência com empresas informais ${ }^{22}$ (Enterprise Surveys, 2009). Essas seriam as barreiras já conhecidas pelo empresário brasileiro, barreiras essas que, embora atinjam, em escalas diferentes, os distintos segmentos empresariais, são genericamente agrupadas no termo Custo Brasil. $^{23}$

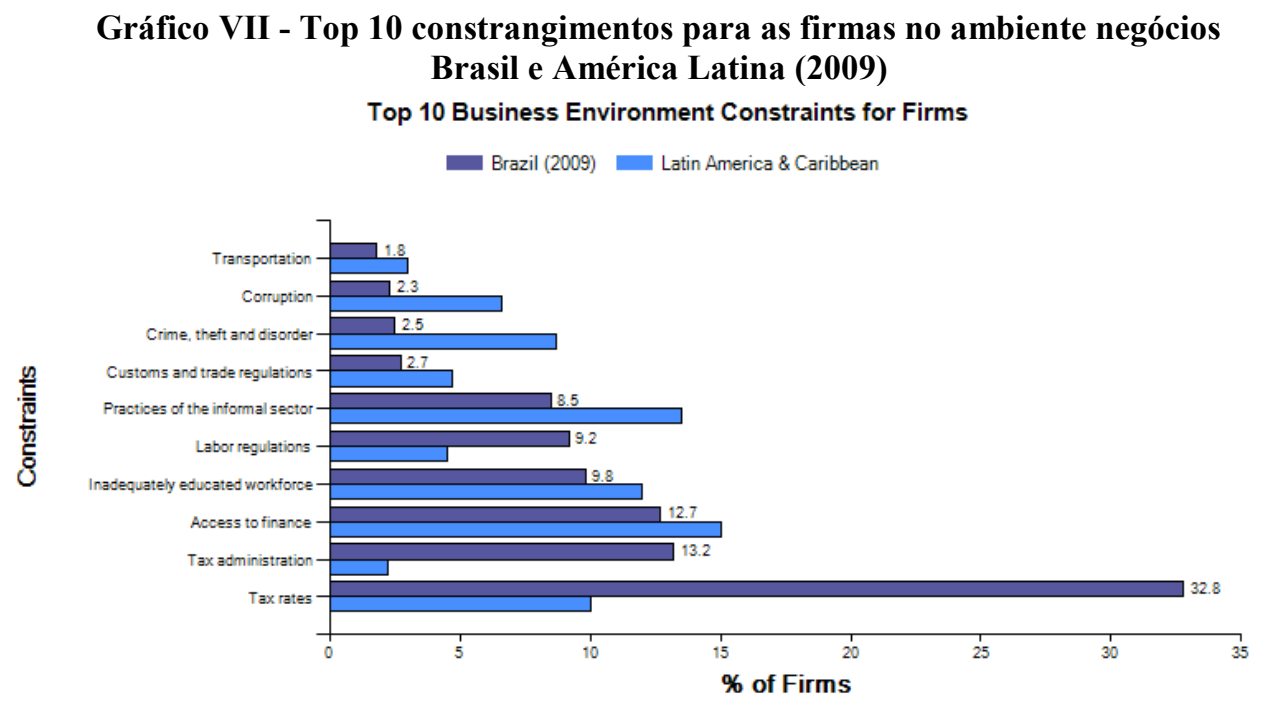

\footnotetext{
${ }^{21}$ Além da própria carga tributária, um dos principais problemas está no tempo gasto na preparação de documentos para pagar impostos, muito acima da média latino-americana. Nesse quesito, o Brasil só perde para Venezuela e México, onde empresários gastam até $34 \%$ e $20 \%$ do seu tempo, respectivamente, lidando com regulações, ao passo que, no Brasil, essa taxa é de 19\%. Ou seja, 19\% do tempo do empresário brasileiro deixa de estar concentrado em atividades produtivas para resolver questões burocráticas, ligadas ao cumprimento dos requisitos legais necessários para manter o funcionamento do negócio.

${ }^{22}$ Para as PMEs, as barreiras associadas à legislação trabalhista são assimiladas como um ônus para manter-se na formalidade, gerando uma linha tênue entre empresas formais e informais.

23 A expressão "Custo Brasil" refere-se, genericamente, aos custos de produção causados por barreiras de infraestrutura e logística, bem como por entraves burocráticos que incidem sobre os regimes produtivos brasileiros. A expressão ganhou popularidade no meio empresarial, nos anos 90 , durante a liberalização econômica, quando essas deficiências estruturais ganharam evidência como um entrave à competitividade da indústria brasileira.
} 
Fonte: World Bank (2009), Enterprise Survey

Não por acaso, a redução do Custo Brasil é uma bandeira que une diferentes setores industriais, sejam eles formados por pequenos, médios ou grande empresários. Segundo relatório publicado pelo Instituto para o Estado do Desenvolvimento Industrial (IEDI), o diagnóstico das condições de produção no Brasil é pouco animador:

O Brasil tem relativamente baixo aumento de produtividade e transformou-se em um país caro demais para produzir, resultado de muitos anos em que, internamente, os custos de toda ordem foram subindo até se tornarem um dos mais altos do mundo. Estamos falando de temas conhecidos como o da tributação, custo de capital de terceiros fora do BNDES, custo do investimento, custo de energia, custo dos encargos trabalhistas e custo de logística." (Carta IEDI, 2012).

Contudo, um olhar mais atento aos custos que atingem o empresariado brasileiro revela um quadro bastante segmentado e assimétrico: enquanto custos econômicos e burocráticos criam barreiras de entrada para novos empreendedores, esses mesmos custos reforçam as vantagens competitivas de grupos econômicos sobre potenciais start-ups locais e multinacionais. Nesse sentido, os maiores entraves a um ambiente de negócios favorável ao empreendedorismo, no Brasil, não são apenas os custos estruturais já conhecidos, o Custo Brasil, mas, principalmente, os efeitos decorrentes das complementaridades negativas, próprias da modalidade hierárquica de capitalismo, que acabam por criar custos diferenciados para pequenos, médios e grandes grupos empresariais, reforçando o big business bias.

\section{CONSIDERAÇÕES FINAIS}

A análise exploratória conduzida neste artigo confirma a hipótese da existência de vícios institucionais (big business bias) que favorecem empresas de grande porte em detrimento de empresa de médio e pequeno porte no acesso a capital, fontes de inovação e na relação interfirmas. O principal argumento do artigo é que esses vícios, decorrentes da modalidade de capitalismo hierárquico, estariam na raíz da dificuldade do capitalismo brasileiro em superar a heterogeneidade estrutural para alcançar um padrão de desenvolvimento mais inclusivo e mais próximo à fronteira tecnológica mundial. Isso porque uma das principais implicações do big business bias é a ativação de barreiras de entrada para a geração de novas riquezas e a manutenção de assimetrias entre setores, regiões e empresas.

A resiliência de dinâmicas societais e políticas hierárquicas coloca em cheque todo esse esforço de renovação e diversificação da matriz econômica brasileira. Se os mecanismos que produzem e reproduzem o big business bias não forem diretamente confrontados, tem-se o 
risco de que as novas riquezas, oriundas do esforço empreendedor, sejam mitigadas pelas barreiras encontradas nos mercados de capitais, nos sistemas de inovação e até mesmo nas relações interfirmas, como apontado por este trabalho.

O problema é que essas assimetrias raramente são objeto de contestação daqueles mais prejudicados pelas barreiras de entrada. Aliás, como grande parte das barreiras aqui discutidas decorre de efeitos indiretos das decisões e ações de um grupo restrito de empresas, que há anos são os principais motores da economia brasileira, o próprio reconhecimento dessas barreiras é extremamente complexo. Além disso, é preciso considerar que questões de caráter regulatório e de apoio industrial são tecnicamente mais complicadas e de pouca visibilidade política, ao contrário de questões macroeconômicas, como abertura comercial, privatização, políticas de câmbio, investimento externo e controle à inflação, que tem servido para criar clivagens políticas e alimentar o debate econômico no país. A principal agenda defendida pelos empresários brasileiros, a redução do Custo Brasil, não leva em consideração as assimetrias e desigualdades observadas entre as empresas. Assim, os mecanismos que reproduzem as vantagens institucionais para os grandes grupos econômicos fazem parte de uma agenda silenciada, ausente do discurso público. Criar uma agenda que lance luz às raízes e implicações do big business bias pode ser o primeiro passo para o reconhecimento dessa dinâmica enquanto um problema de natureza política e econômica.

Portanto, além dos inúmeros desafios inerentes ao processo de transformação econômica estrutural necessário para o catch up tecnológico, o Brasil precisará enfrentar ainda o desafio de romper com dinâmicas institucionais hierárquicas e excursionarias que beneficiam a elite econômica deste país há décadas.

\section{REFERÊNCIAS BIBLIOGRÁFICAS}

ACEMOGLU, D.; JOHNSON, S.; ROBINSON, J. A. Institutions as a Fundamental Cause of Long-Run Growth. In: AGHION, Philippe and DURLAUF, Steven N. Handbook of Economic Growth. Elsevier v. 1, 2005

AGUILERA, R. V et al. Corporate Governance in Emerging Markets. In: MORGAN, G.; WHITLEY, R. (Eds.). Capitalisms and Capitalism in the 21st Century. Oxford University Press, 2012

ALDRIGHI, D. M. As Ofertas Públicas Iniciais na Bovespa no Período Recente: Características das Empresas, Estrutura de Propriedade e de Controle, e Desempenho. p. 138, Publicações BNDES, 2008. Disponível em: $<$ http://www.bndes.gov.br/SiteBNDES/export/sites/default/bndes pt/Galerias/Arquivos/produ tos/download/pde/PDE2009 IPE-USP Aldrighi.pdf $>$ Último acesso em 22/03/15 
ALDRIGHI, D. M.; ANTONIO, F.; POSTALI, S. Propriedade Piramidal das Empresas no Brasil. p. 2011. 27-48, Disponível em: $<$ http://www.anpec.org.br/revista/vol12/vol12n1p27_48.pdf > Último acesso em 22/03/15

ALLEN, M. The varieties of capitalism paradigm: not enough variety? Socio-Economic Review, v. 2, n. 1, p. 87-108, 1 jan. 2004.

AMSDEN, A. H. The rise of "the rest": Challenges to the West from Late-Industrializing Economies. Oxford University Press, 2001

ATERIDO, R.; HALLWARD-DRIEMIER, M.; PAGES, C. Big Constraints to Small Firms' Growth? Business Environment and Employment Growth across Firms. Policy Research Working Paper. World Bank, 2009. Disponível em: < http://elibrary.worldbank.org/doi/pdf/10.1596/1813-9450-5032 > Último acesso em 22/03/15

BECK, T.; DEMIRGUCKUNT, A.; MAKSIMOVIC, V. Financing patterns around the world: Are small firms different? Journal of Financial Economics, v. 89, n. 3, p. 467-487, set. 2008.

BOYER, R. How and why capitalisms differ. Economy and society, 2005.

COLPAN, A. M.; HIKINO, T.; LINCOLN, J. R. Foundations of Business Groups: towards an integrated framework. In: (Eds.).The Oxford Handbook of Business Groups. Oxford University Press, 2010.

CVM. Mercado de valores mobiliários brasileiro. 1 ed. Rio de Janeiro, 2013.

DELIOS, A.; MA, X. Diversification Strategy and Business Groups. In: COLPAN, A. M.; HIKINO, T.; LINCOLN, J. R. (Eds.).The Oxford Handbook of Business Groups. [s.1.] Oxford University Press, 2010.

DELOITTE. Um estudo sobre empresas que cultivam as bases de sua expansão. Revista Exame PME, 2010 (As PMES que mais crescem no Brasil)

DELOITTE. Empresas e empreendedores: o novo ranking das PMEs e um perfil dos líderes das emergentes. Revista Exame PME, 2013 (As PMES que mais crescem no Brasil).

ESTRIN, S.; PREVEZER, M. A survey on institutions and new firm entry: How and why do entry rates differ in emerging markets? Economic Systems, v. 34, n. 3, p. 289-308, set. 2010.

GILSON, R.; BLACK, B. Venture capital and the structure of capital markets: banks versus stock markets. Journal of Financial Economics, 1998.

HALL, PA; SOSKICE D, eds. Varieties of Capitalism: The Institutional Foundations of Comparative Advantage. New York: Oxford Univ. Press, 2001

HALL, PA; THELEN, K. Institutional change in varieties of capitalism. Soc. Econ. Rev. 7:734, 2009

HERRENDORF, B.; TEIXEIRA, A. Barriers To Entry and Development. International Economic Review, v. 52, n. 2, p. 573-602, 25, maio 2011. 
IBGE. Estatística de Empreendedorismo - 2011, Rio de Janeiro, 2013

IBGE. Pesquisa de Inovação 2011 - PINTEC, Rio de Janeiro, 2013

IEDI - INSTITUTO DE ESTUDOS PARA O DESENVOLVIMENTO INDUSTRIAL. Indústria, Desenvolvimento e Política Industrial. Carta IEDI n. 530, 2012.

JACKSON, G.; DEEG, R. How many varieties of capitalism? Comparing the comparative institutional analyses of capitalist diversity. MPIFG Discussion Paper 06/2, 2006.

JONES, G.; COLPAN, A. M. Business Groups in Historical Perspectives. In: COLPAN, A. M.; HIKINO, T.; LINCOLN, J. R. (Eds.). The Oxford Handbook of Business Groups. [s.1.] Oxford University Press, 2010.

KHANNA, T.; YAFEK, Y. Business groups in Emerging Markets: Paragons or Parasites? In: COLPAN, A. M.; HIKINO, T.; LINCOLN, J. R. (Eds.). The Oxford Handbook of Business Groups. [s.1.] Oxford University Press, 2010.

KPMG; ASSOCIAÇÃO BRASILEIRA DE PRIVATE EQUITY \& VENTURE CAPITAL ABVCAP. Consolidação de Dados da Indústria de Private Equity e Venture Capital no Brasil, 2016.

KUMAR, A. Access to Financial services in Brazil. The World Bank, 2005.

LA PORTA, R., LOPEZ-DE-SILANES, F., SHLEIFER, A., Vishny, R. The quality of government. Journal of Law, Economics and Organization 15, 1999

LAZZARINI, S. Capitalismo de laços: os dono do Brasil e suas conexões. SP Campus, 2011.

MAHONEY, J. Colonialism and postcolonial development: Spanish America in comparative perspective. Cambridge University Press, 2010

MORCK, Randall; STEIER, LLyod. A History of Corporate Governance around the World: Family Business Groups to Professional Managers Publication. University of Chicago Press, 2005

OLIN, J. M.; GILSON, R. J.; BLACK, B. Does Venture Capital require an Active Stock Market? Journal of Applied Corporate Finance. v. 48, n. 166, 1999.

SCHAPIRO, M. G. Novos parâmetros para a intervenção do estado na economia: persistência e dinâmica na atuação do BNDES em uma economia baseada no conhecimento. Tese (Doutorado em Econômico e Financeiro). Universidade de São Paulo, 2009.

SCHNEIDER, B. R. A comparative political economy of diversified business groups, or how states organize big business. Review of International Political Economy, n. May 2013, p. 3741, 2009

SCHNEIDER, B. R. Business Groups and the State: The Politics of Expansion, Restructuring and Collapse. In: COLPAN, A. M.; HIKINO, T.; LINCOLN, J. R. (Eds.). The oxford Handbook of Business Groups. [s.1.] Oxford University Press, 2010. p. 1-31. 
SCHNEIDER, B. R. Hierarchical Capitalism in Latin America: Business, Labor, and the Challenge of Equitable Development. New York: Cambridge University Press, 2013

THELEN, K. Varieties of Capitalism: Trajectories of Liberalization and the New Politics of Social Solidarity. Annual Review of Political Science, v. 15, n. 1, p. 137-159, 15 jun. 2012.

WOLFENZON, D.; YEUNG, B.; MORCK, R. K. Corporate Governance, Economic Entrenchment, and Growth. Journal of Economic Literature, v. 43, n. 3, p. 655-720, 2005.

WORLD BANK, Doing Business Report, 2009

WORLD BANK. Enterprise Survey, 2009

ZAMBALDI, F. et al. Credit granting to small firms: A Brazilian case. Journal of Business Research, v. 64, n. 3, p. 309-315, mar. 2011.

ZOLTÁN, J.; VIRGILL, N. Entrepreneurship in developing countries. Jena economic research papers, No. 023, 2009. Disponível em: < http://hdl.handle.net/10419/31789 > Último acesso em 22/03/15. 